\title{
Anesthetic management of a patient with Freeman-Sheldon syndrome undergoing oral surgery: A case report
}

Aiji Sato $(B o k u)^{1}$, Yoshiki Sento ${ }^{2}$, Tatsuya Hasegawa ${ }^{2}$, Kosuke Tsutsumi ${ }^{2}$, Yuji Kamimura ${ }^{2}$, MinHye $\mathrm{So}^{2}$, Eisuke $\mathrm{Kako}^{2}$, and Kazuya Sobue ${ }^{2}$

${ }^{1}$ Aichi Gakuin University School of Dentistry

${ }^{2}$ Nagoya City University Graduate School of Medical Sciences and Medical School

April 13, 2021

\begin{abstract}
Freeman-Sheldon syndrome (FSS) is characterized by multiple joint contractures, characteristic facial features, such as microtia, defects of the hands and feet, such as clubfoot, and skeletal malformations. This report illustrates the case of a patient with FSS who was managed under local anesthesia with intravenous sedation for oral surgery.
\end{abstract}

\section{Hosted file}

FSS_Clinical Case Reports Manuscript.pdf available at https://authorea.com/users/344519/ articles/517832-anesthetic-management-of-a-patient-with-freeman-sheldon-syndromeundergoing-oral-surgery-a-case-report 


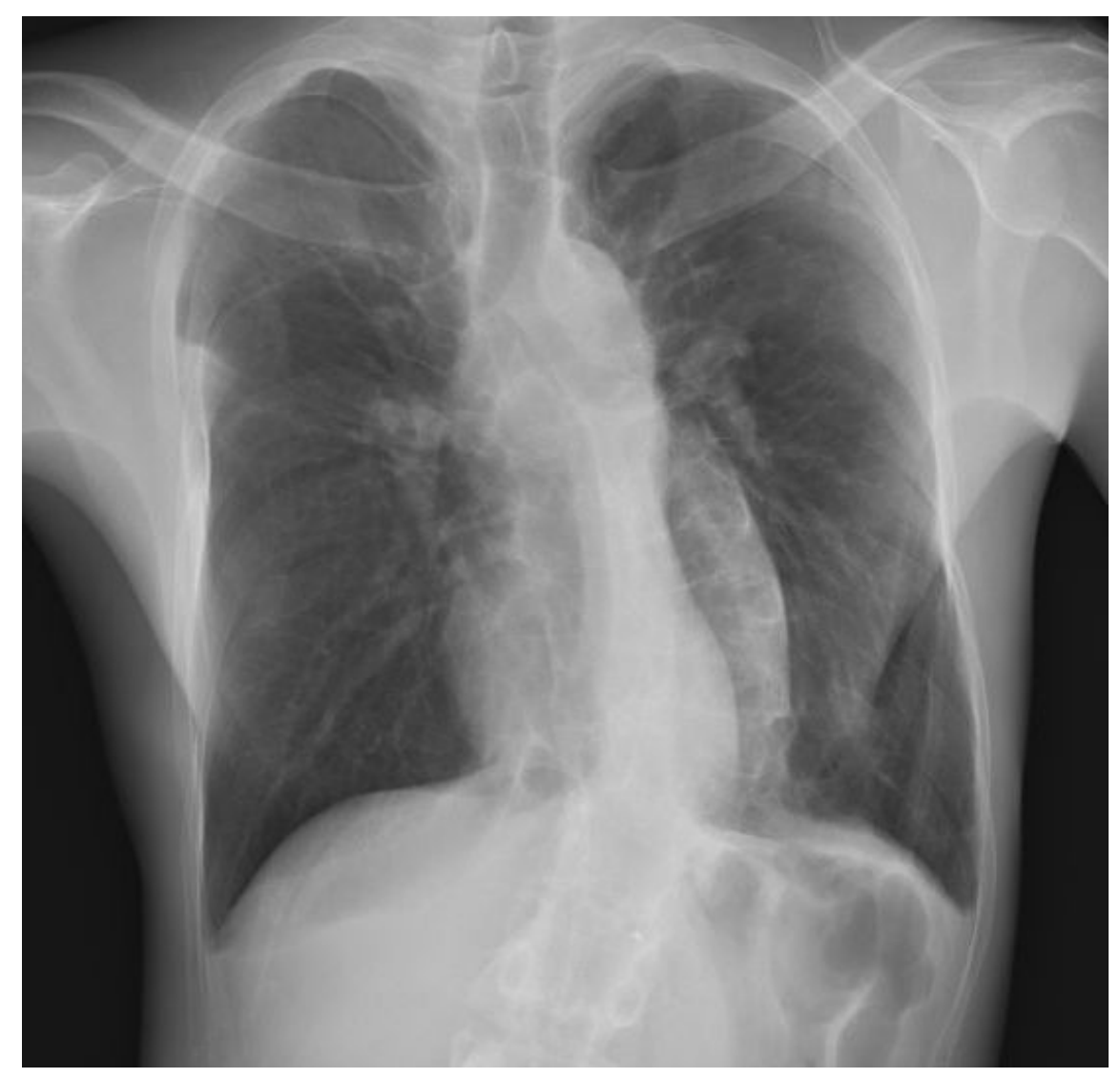

